\title{
Effects of propranolol on the development of glucocorticoid-induced osteoporosis in male rats
}

\author{
Joanna Folwarczna, Maria Pytlik, Leszek Śliwiński, Urszula Cegieła, \\ Barbara Nowińska, Monika Rajda \\ Department of Pharmacology, Medical University of Silesia, Katowice, Jagiellońska 4, PL 41-200 Sosnowiec, \\ Poland
}

Correspondence: Joanna Folwarczna, e-mail: jfolwarczna@sum.edu.pl

\begin{abstract}
:
Glucocorticoid-induced osteoporosis is the most frequently occurring type of secondary osteoporosis. Antagonists of $\beta$-adrenergic receptors are now considered to be potential drugs under investigation for osteoporosis. The aim of the present study was to investigate the effects of propranolol, a nonselective $\beta$-receptor antagonist, on the skeletal system of mature male rats and on the development of bone changes induced by glucocorticoid (prednisolone) administration. The experiments were performed on 24-week-old male Wistar rats. The effects of prednisolone 21 -hemisuccinate sodium salt ( $7 \mathrm{mg} / \mathrm{kg}, s c$ daily) or/and propranolol hydrochloride $(10 \mathrm{mg} / \mathrm{kg}$, ip daily) administered for 4 weeks on the skeletal system were studied. Bone and bone mineral mass in the tibia, femur and L-4 vertebra, length and diameter of the long bones, mechanical properties of tibial metaphysis, femoral diaphysis and femoral neck, bone histomorphometric parameters and turnover markers in serum were determined. Prednisolone-induced unfavorable skeletal changes led to disorders in bone mechanical properties. Propranolol not only did not improve bone parameters, but even caused deleterious effects on the skeletal system. Concurrent administration of propranolol with prednisolone did not counteract the changes induced by prednisolone. The results of this study may help to understand the equivocal results of human studies on the effects of $\beta$-blockers on the skeletal system. It is possible that the drugs exert biphasic effects on the skeletal system, both favorable and deleterious, depending on the dose or individual susceptibility.
\end{abstract}

Key words:

propranolol, prednisolone, bone histomorphometry, bone mechanical properties, bone mineralization

\section{Introduction}

An excess of glucocorticoids is a factor that is well known to damage the skeletal system, predominantly due to the inhibition of bone formation [11]. Glucocorticoid-induced osteoporosis is the most frequently occurring type of secondary osteoporosis $[9,40]$. For the treatment of glucocorticoid-induced osteoporosis, usually bisphosphonates, which are antiresorptive agents, are used [10, 11, 40]. However, anabolic treatment with teriparatide seems to be an attractive alternative treatment option [40].
$\beta$-Blockers are now considered to be potential drugs under investigation for osteoporosis and fracture healing [18]. It was demonstrated that activation of $\beta_{2}$-adrenergic receptors in osteoblasts and stromal cells leads to the inhibition of bone formation and intensification of bone resorption [36, 37]. Propranolol, a nonselective $\beta$-receptor antagonist, was reported to be effective in counteracting bone damage in different experimental models of bone disorders [1, 6, 22, 31, $34,35,42]$. Results of some, but not all, human studies $[5,12,23,27-30,32,41]$ confirm the hypothesis that $\beta$-blockers may decrease the fracture rate. 
The effects of $\beta$-receptor antagonists on bone damage caused by an excess of glucocorticoids have not been reported so far. The aim of this study was to investigate the effects of $\beta$-adrenergic receptor blockade by propranolol on the skeletal system of mature male rats and on the development of bone changes induced by glucocorticoid (prednisolone) administration.

\section{Materials and Methods}

Experiments were performed on mature 24-week-old male Wistar rats obtained from the Center of Experimental Medicine, Medical University of Silesia. The rats were fed a standard diet ad libitum. The protocol for the experiments on animals was approved by Local Ethics Commission, Katowice, Poland.

Drugs used: propranolol hydrochloride (SigmaAldrich, at a dose of $10 \mathrm{mg} / \mathrm{kg}$, ip daily), prednisolone 21-hemisuccinate sodium salt (Sigma-Aldrich, at a dose of $7 \mathrm{mg} / \mathrm{kg}, s c$ daily).

The animals were divided into 4 groups: I, control rats $(\mathrm{n}=10)$; II, rats receiving prednisolone $(\mathrm{n}=9)$; III, rats receiving propranolol $(\mathrm{n}=8)$; IV, rats receiving prednisolone and propranolol $(n=8)$. The drugs were administered once daily for 4 weeks. Each rat was given two injections: $s c$ (prednisolone or the $0.9 \% \mathrm{NaCl}$ vehicle, at a volume of $1 \mathrm{ml} / \mathrm{kg}$ ) and ip (propranolol or the $0.9 \% \mathrm{NaCl}$ vehicle, at a volume of $1 \mathrm{ml} / \mathrm{kg}$ ).

The animals were given tetracycline hydrochloride $(20 \mathrm{mg} / \mathrm{kg}$, ip) to mark the calcification front one day before the start and on the last day of drug or vehicle administration. The day following the last drug administration, the animals were anesthetized with ketamine and xylazine. After collection of blood samples by heart puncture, animals were sacrificed. The tibias, femurs and L-4 vertebra were excised. In the bones isolated from the left side, the mass and macrometric parameters were determined (length and diameter of the diaphysis at mid-length). The vertebrae were weighed. The left femurs and tibias, and proximal part of the right femurs, were wrapped in gauze moisturized with $0.9 \% \mathrm{NaCl}$ solution and kept below $-20^{\circ} \mathrm{C}$ until the mechanical tests were performed [39]. The mass of the adrenal glands was also determined.

\section{Bone mechanical property studies}

Mechanical properties of the tibial metaphysis and femoral diaphysis in bending tests and the femoral neck in a compression test were studied using an Instron $3342500 \mathrm{~N}$ apparatus. The data were analyzed by Bluehill 2 version 2.14 software (Instron).

Mechanical properties of the diaphysis of the left femurs were studied using a bending test with threepoint loading [39]. The distance between the supporting points was $20 \mathrm{~mm}$. The load was applied perpendicularly to the long axis of the femur at the mid-length of the bone. To obtain steady positioning, five cycles of pre-conditioning (displacement rate of $0.01 \mathrm{~mm} / \mathrm{s}, 4 \mathrm{~N}$ limit) were performed, and then the mechanical test was started (displacement rate of $0.02 \mathrm{~mm} / \mathrm{s}$, sampling rate of $100 \mathrm{~Hz}$ ). The load-displacement curves obtained for each bone, representing the relationships between the load applied to the bone and the displacement in response to the load, were analyzed. Maximal load, displacement for the maximal load and energy for the maximal load were determined.

The mechanical strength of the femoral neck was studied using a compression test. The bone was prepared for measurement by fixing the diaphysis, which was cut at the mid-length of the femur, in a methacrylate plate [16]. The load was applied to the head of the femur along the long axis of the femur (preload of $1 \mathrm{~N}$, displacement rate of $0.01 \mathrm{~mm} / \mathrm{s}$ ). The load causing the fracture of the femoral neck (maximal load) was determined.

The mechanical properties of the proximal metaphysis of the left tibia were studied using a bending test with three-point loading as described by Stürmer et al. [33], after a preload of $1 \mathrm{~N}$, with a displacement rate of $0.02 \mathrm{~mm} / \mathrm{s}$. The maximal load, displacement for the maximal load and energy for the maximal load were assessed.

\section{Bone mineralization studies}

The L-4 vertebra, left tibia and femur were lyophilized for 5 days to determine the dehydrated bone mass. To determine the mass of bone mineral, the L-4 vertebra, left tibia and femur were mineralized at $640^{\circ} \mathrm{C}$ for $48 \mathrm{~h}$ in a muffle furnace and weighed. To determine whether the changes in bone mass parameters were related to the changes in the body mass caused by the treatments, results concerning bone mass, lyophilized bone mass and mass of bone min- 
eral were also determined as ratios to body mass. The ratios of bone mineral mass to bone mass and to lyophilized bone mass were determined as substitutes for bone mineral density measurements.

Calcium content in the mineralized bones dissolved in $6 \mathrm{M} \mathrm{HCl}$ and then diluted in distilled water was determined colorimetrically, using a kit produced by Pointe Scientific, Inc.

\section{Bone histomorphometric studies}

The histological specimens were prepared from right femoral and tibial bones as previously described [14, 15]. Histomorphometric measurements were made using an Optiphot-2 microscope (Nikon), connected through an RGB camera (Cohu) to a personal computer (program Lucia G 4.51, Laboratory Imaging), with final magnifications of 200 and 500 times, and a lanameter (magnification 50 times).

The periosteal and endosteal transverse growth and the width of the endosteal osteoid were determined in transverse cross-sections made from the tibial diaphysis. The area of the transverse cross-section of the cortical bone and the area of the transverse cross-section of the marrow cavity were measured in transverse cross-sections made from the femoral diaphysis at the mid-length of the femur. In the longitudinal preparation from the femur, the width of epiphyseal cartilage and the width of trabeculae in the epiphysis and metaphysis were measured.

\section{Biochemical studies}

Serum osteocalcin levels were determined using an enzyme immunoassay (Rat-MID ${ }^{\mathrm{TM}}$ Osteocalcin EIA, Immunodiagnostic Systems Ltd.). Osteoclast-derived serum tartrate-resistant acid phosphatase form $5 \mathrm{~b}$ (TRACP 5b) levels were determined by a solid-phase immunofixed enzyme activity assay (RatTRAPTM Assay, Immunodiagnostic Systems Ltd.).

\section{Statistical analysis}

Results are presented as the mean \pm SEM. One-way ANOVA followed by Duncan's test or, when appropriate, Kruskal-Wallis ANOVA followed by MannWhitney $U$ test were used to evaluate the statistical significance of the results. The results obtained in each experimental group were compared with those of the control rats. Moreover, the results obtained in rats receiving prednisolone and propranolol concurrently were compared with those of rats receiving prednisolone or propranolol alone.

\section{Results}

\section{Effects of prednisolone}

After a 4-week administration of prednisolone 21hemisuccinate sodium salt ( $7 \mathrm{mg} / \mathrm{kg}, s c$ daily) to male rats, body mass gain and adrenal gland mass significantly decreased (Tab. 1). The mass of bones immediately after isolation, mass of lyophilized bones, mass of bone mineral and calcium content in the bone mineral were not significantly affected in comparison to the control group (data not shown). The ratios of bone mass, lyophilized bone mass and bone mineral mass to the body mass and the ratio of bone mineral mass to bone mass slightly tended to increase or were unaffected (Tab. 2, data for the tibia not shown).

Tab. 1. Effects of prednisolone 21-hemisuccinate sodium salt ( $7 \mathrm{mg} / \mathrm{kg}$, sc daily) and propranolol hydrochloride (10 mg/kg, ip daily) administered for 4 weeks on body mass gain and mass of adrenal glands and in rats

\begin{tabular}{lcccc}
\hline \multicolumn{1}{c}{ Parameter/Group } & Control & Prednisolone & Propranolol & Prednisolone + propranolol \\
\hline Body mass at the start of drug administration $(\mathrm{g})$ & $365.1 \pm 8.9$ & $370.4 \pm 12.6$ & $363.6 \pm 9.1$ & $364.3 \pm 7.9$ \\
Body mass gain after 4 weeks $(\mathrm{g})$ & $15.9 \pm 5.3$ & $-7.9 \pm 4.5^{\star}$ & $11.6 \pm 4.5$ & $-22.3 \pm 3.2^{* \star \star a b b b}$ \\
Adrenal mass $(\mathrm{g})$ & $0.046 \pm 0.003$ & $0.034 \pm 0.003^{\star}$ & $0.047 \pm 0.005$ & $0.038 \pm 0.003$ \\
\hline
\end{tabular}

Results are presented as the mean \pm SEM $(n=8-10)$. One-way ANOVA followed by Duncan's test or, when appropriate, Kruskal-Wallis ANOVA followed by Mann-Whitney $U$ test was used to evaluate the significance of the results. ${ }^{\star} p<0.05$, ${ }^{\star * *} p<0.001$ when compared to the control rats. ${ }^{a} p<0.05$ when compared to the rats receiving prednisolone, ${ }^{b b b} p<0.001$ when compared to the rats receiving propranolol 
Tab. 2. Effects of prednisolone 21 -hemisuccinate sodium salt ( $7 \mathrm{mg} / \mathrm{kg}, \mathrm{sc}$ daily) and propranolol hydrochloride (10 mg/kg, ip daily) administered for 4 weeks on bone mass and mineralization in rats

\begin{tabular}{|c|c|c|c|c|c|}
\hline Parameter/Group & & Control & Prednisolone & Propranolol & $\begin{array}{l}\text { Prednisolone + } \\
\text { propranolol }\end{array}$ \\
\hline \multirow{2}{*}{$\begin{array}{l}\text { Bone mass/body mass ( } \mathrm{g} / 100 \mathrm{~g} \\
\text { of body mass) }\end{array}$} & Femur & $0.283 \pm 0.004$ & $0.288 \pm 0.003$ & $0.270 \pm 0.006^{*}$ & $0.308 \pm 0.003^{\star \star *}$ a a bbb \\
\hline & L-4 vertebra & $0.090 \pm 0.002$ & $0.093 \pm 0.002$ & $0.084 \pm 0.004$ & $0.092 \pm 0.003$ \\
\hline \multirow{2}{*}{$\begin{array}{l}\text { Lyophilized bone mass/body mass } \\
\text { ( } \mathrm{g} / 100 \mathrm{~g} \text { of body mass) }\end{array}$} & Femur & $0.197 \pm 0.003$ & $0.203 \pm 0.002$ & $0.189 \pm 0.003$ & $0.219 \pm 0.002^{\star * \star}$ aaa bbb \\
\hline & L-4 vertebra & $0.057 \pm 0.001$ & $0.060 \pm 0.002$ & $0.053 \pm 0.002$ & $0.062 \pm 0.002^{\mathrm{bb}}$ \\
\hline \multirow{2}{*}{$\begin{array}{l}\text { Bone mineral mass/body mass } \\
\text { ( } \mathrm{g} / 100 \mathrm{~g} \text { of body mass) }\end{array}$} & Femur & $0.120 \pm 0.002$ & $0.124 \pm 0.001$ & $0.116 \pm 0.002$ & $0.133 \pm 0.002^{* *}$ aa bbb \\
\hline & $L-4$ vertebra & $0.032 \pm 0.001$ & $0.034 \pm 0.001$ & $0.031 \pm 0.001$ & $0.036 \pm 0.001^{\star b b b}$ \\
\hline \multirow[t]{2}{*}{ Bone mineral mass/bone mass ratio } & Femur & $0.426 \pm 0.004$ & $0.432 \pm 0.004$ & $0.432 \pm 0.008$ & $0.432 \pm 0.006$ \\
\hline & $L-4$ vertebra & $0.362 \pm 0.006$ & $0.364 \pm 0.004$ & $0.362 \pm 0.006$ & $0.391 \pm 0.010^{*} \mathrm{aab}$ \\
\hline \multirow{2}{*}{$\begin{array}{l}\text { Bone mineral mass/lyophilized bone } \\
\text { mass ratio }\end{array}$} & Femur & $0.611 \pm 0.007$ & $0.614 \pm 0.005$ & $0.615 \pm 0.004$ & $0.608 \pm 0.008$ \\
\hline & $L-4$ vertebra & $0.565 \pm 0.006$ & $0.562 \pm 0.005$ & $0.572 \pm 0.006$ & $0.577 \pm 0.009$ \\
\hline Femur length (mm) & & $40.42 \pm 0.26$ & $39.98 \pm 0.29$ & $39.95 \pm 0.35$ & $40.34 \pm 0.24$ \\
\hline Femur diameter (mm) & & $3.90 \pm 0.04$ & $3.84 \pm 0.04$ & $3.64 \pm 0.07^{\star \star}$ & $3.88 \pm 0.06^{\mathrm{bb}}$ \\
\hline
\end{tabular}

Results are presented as the mean \pm SEM $(n=8-10)$. One-way ANOVA followed by Duncan's test or, when appropriate, Kruskal-Wallis ANOVA followed by Mann-Whitney U test was used to evaluate the significance of the results. ${ }^{*} p<0.05,{ }^{* *} p<0.01$, ${ }^{\star * *} p<0.001$ when compared to the control rats. ${ }^{a a} p<0.01$, aaa $p<0.001$ when compared to the rats receiving prednisolone, ${ }^{b} p<0.05,{ }^{b b} p<0.01$, ${ }^{b b b} p<0.001$ when compared to the rats receiving propranolol

Tab. 3. Effects of prednisolone 21 -hemisuccinate sodium salt ( $7 \mathrm{mg} / \mathrm{kg}$, sc daily) and propranolol hydrochloride (10 mg/kg, ip daily) administered for 4 weeks on bone mechanical properties in rats

\begin{tabular}{|c|c|c|c|c|c|}
\hline \multicolumn{2}{|l|}{ Parameter/Group } & \multirow{2}{*}{$\begin{array}{c}\text { Control } \\
155.04 \pm 5.23\end{array}$} & \multirow{2}{*}{$\begin{array}{l}\text { Prednisolone } \\
150.48 \pm 6.07\end{array}$} & \multirow{2}{*}{$\begin{array}{c}\text { Propranolol } \\
148.67 \pm 7.05\end{array}$} & \multirow{2}{*}{$\begin{array}{c}\begin{array}{c}\text { Prednisolone } \\
\text { propranolol }\end{array} \\
157.89 \pm 7.85\end{array}$} \\
\hline & Maximal load (N) & & & & \\
\hline \multirow[t]{2}{*}{ Femoral diaphysis } & Displacement for maximal load (mm) & $0.698 \pm 0.028$ & $0.695 \pm 0.031$ & $0.658 \pm 0.038$ & $0.716 \pm 0.038$ \\
\hline & Energy for maximal load (J) & $0.069 \pm 0.005$ & $0.067 \pm 0.006$ & $0.061 \pm 0.006$ & $0.074 \pm 0.007$ \\
\hline \multicolumn{2}{|l|}{ Femoral neck - maximal load (N) } & $124.23 \pm 5.52$ & $131.44 \pm 4.82$ & $115.10 \pm 5.06$ & $117.34 \pm 5.84$ \\
\hline \multirow{3}{*}{ Tibial metaphysis } & Maximal load (N) & $99.82 \pm 5.58$ & $88.17 \pm 5.68$ & $83.70 \pm 7.00$ & $82.45 \pm 4.61$ \\
\hline & Displacement for maximal load (mm) & $1.230 \pm 0.089$ & $0.925 \pm 0.085$ & $1.025 \pm 0.111$ & $1.022 \pm 0.122$ \\
\hline & Energy for maximal load (J) & $0.075 \pm 0.008$ & $0.049 \pm 0.004^{*}$ & $0.055 \pm 0.007$ & $0.054 \pm 0.007$ \\
\hline
\end{tabular}

Results are presented as the mean \pm SEM $(n=8-10)$. One-way ANOVA followed by Duncan's test was used to evaluate the significance of the results. ${ }^{\star} p<0.05$ when compared to the control rats 
Tab. 4. Effects of prednisolone 21 -hemisuccinate sodium salt ( $7 \mathrm{mg} / \mathrm{kg}, \mathrm{sc}$ daily) and propranolol hydrochloride (10 mg/kg, ip daily) administered for 4 weeks on bone histomorphometric parameters in rats

\begin{tabular}{|c|c|c|c|c|c|}
\hline Parameter/Group & & Control & Prednisolone & Propranolol & $\begin{array}{l}\text { Prednisolone + } \\
\text { propranolol }\end{array}$ \\
\hline Width of endosteal osteoid in the tibia ( $\mu \mathrm{m})$ & & $8.29 \pm 0.21$ & $7.49 \pm 0.22^{*}$ & $6.20 \pm 0.37^{\star \star \star}$ & $6.80 \pm 0.24^{\star \star \star}$ \\
\hline \multirow[t]{2}{*}{ Transverse growth of the tibia $(\mu \mathrm{m})$} & Periosteal & $23.15 \pm 2.62$ & $14.13 \pm 1.27^{\star}$ & $17.14 \pm 1.36$ & $13.41 \pm 1.18^{\star \star}$ \\
\hline & Endosteal & $8.12 \pm 0.31$ & $8.09 \pm 0.27$ & $7.50 \pm 0.11$ & $9.90 \pm 1.32$ \\
\hline $\begin{array}{l}\text { Transverse cross-sectional area of the cortical } \\
\text { bone in the femoral diaphysis }\left(\mathrm{mm}^{2}\right)\end{array}$ & & $6.66 \pm 0.25$ & $6.52 \pm 0.20$ & $6.08 \pm 0.17$ & $6.75 \pm 0.40$ \\
\hline $\begin{array}{l}\text { Transverse cross-sectional area of the marrow } \\
\text { cavity in the femoral diaphysis }\left(\mathrm{mm}^{2}\right)\end{array}$ & & $4.28 \pm 0.12$ & $3.89 \pm 0.18$ & $3.65 \pm 0.11^{\star \star}$ & $3.98 \pm 0.27$ \\
\hline Femoral marrow cavity/diaphysis area ratio & & $0.392 \pm 0.009$ & $0.373 \pm 0.012$ & $0.375 \pm 0.008$ & $0.371 \pm 0.014$ \\
\hline \multirow[t]{2}{*}{ Width of trabeculae in the femur ( $\mu \mathrm{m})$} & Epiphysis & $55.0 \pm 0.60$ & $43.07 \pm 0.82^{\star \star *}$ & $44.34 \pm 0.98^{\star \star *}$ & $43.84 \pm 0.70^{\star * \star}$ \\
\hline & Metaphysis & $43.84 \pm 0.86$ & $36.76 \pm 0.74^{\star \star \star}$ & $37.07 \pm 1.22^{\star \star \star}$ & $36.58 \pm 1.01^{\star \star *}$ \\
\hline Width of epiphyseal cartilage in the femur ( $\mu \mathrm{m})$ & & $83.97 \pm 3.62$ & $78.74 \pm 4.98$ & $71.34 \pm 3.18$ & $69.21 \pm 3.56$ \\
\hline
\end{tabular}

Results are presented as the mean \pm SEM $(n=8-10)$. One-way ANOVA followed by Duncan's test or, when appropriate, Kruskal-Wallis ANOVA followed by Mann-Whitney $U$ test was used to evaluate the significance of the results. ${ }^{*} p<0.05,{ }^{* *} p<0.01$, ${ }^{\star * *} p<0.001$ when compared to the control rats

Tab. 5. Effects of prednisolone 21-hemisuccinate sodium salt (7 mg/kg, sc daily) and propranolol hydrochloride (10 mg/kg, ip daily) administered for 4 weeks on serum bone turnover markers in rats

\begin{tabular}{lcccc}
\hline \multicolumn{1}{c}{ Parameter/Group } & Control & Prednisolone & Propranolol & Prednisolone + propranolol \\
\hline Osteocalcin (ng/ml) & $267.0 \pm 19.0$ & $238.0 \pm 13.8$ & $214.7 \pm 10.3^{*}$ & $181.8 \pm 8.6^{\star \star \star ~ a a ~}$ \\
TRACP 5b (U/l) & $3.05 \pm 0.12$ & $2.45 \pm 0.20^{*}$ & $2.78 \pm 0.14$ & $2.38 \pm 0.24^{\star *}$ \\
\hline
\end{tabular}

Results are presented as the mean \pm SEM $(n=8-10)$. One-way ANOVA followed by Duncan's test or, when appropriate, Kruskal-Wallis ANOVA followed by Mann-Whitney $U$ test was used to evaluate the significance of the results. ${ }^{*} p<0.05,{ }^{* \star} p<0.01$, ${ }^{\star * \star} p<0.001$ when compared to the control rats. ${ }^{\text {aa }} \mathrm{p}<0.01$ when compared to the rats receiving prednisolone

The excess of glucocorticosteroids significantly impaired the mechanical properties of the cancellous bone of the tibial metaphysis: the energy for the maximal load was decreased, and the maximal load and the displacement for the maximal load tended to decrease in comparison to the control rats (Tab. 3). Prednisolone administration did not significantly affect the mechanical properties of the femoral diaphysis and the femoral neck.

Histomorphometric analysis of the compact bone showed a decreased osteoid width, periosteal transverse growth in the tibia and a tendency to decrease the transverse cross-sectional area of the femoral marrow cavity after prednisolone administration in relation to the control group (Tab. 4). In the cancellous bone of the femur, the width of trabeculae was also decreased.

The serum levels of TRACP $5 b$ significantly decreased and those of osteocalcin tended to decrease after prednisolone administration in comparison to the controls (Tab. 5).

\section{Effects of propranolol}

Administration of propranolol hydrochloride $(10 \mathrm{mg} /$ $\mathrm{kg}$, ip daily) did not affect the body mass gain and the mass of the adrenal glands (Tab. 1). The mass of 
bones immediately after isolation, mass of lyophilized bones, mass of bone mineral (data not shown) and the ratios of bone mass, lyophilized bone mass and bone mineral mass to the body mass slightly tended to decrease in comparison to the control group (Tab. 2, data for the tibia not shown). The ratio of the bone mass to the body mass and the diameter of the femur significantly decreased in comparison to the control rats. Calcium content in the bone mineral was not significantly affected (data not shown).

After administration of propranolol, mechanical properties of the tibial metaphysis tended to be worse in comparison to controls (Tab. 3). The maximal load and the energy for maximal load were strongly decreased; however, the changes did not reach statistical significance. The unfavorable effects of propranolol on the mechanical properties of the femoral diaphysis and neck were not significant.

In the compact bone of the tibia, propranolol decreased the osteoid width and strongly tended to decrease transverse growth. In the femur, propranolol decreased the transverse cross-sectional area of the marrow cavity and tended to decrease that of the cortical bone (Tab. 4). Propranolol also decreased the width of trabeculae (significantly) and epiphyseal cartilage.

Administration of propranolol did not markedly affect serum TRACP 5 b levels, but it significantly decreased osteocalcin concentration (Tab. 5).

\section{Effects of concurrent administration of propra- nolol and prednisolone}

Propranolol hydrochloride $(10 \mathrm{mg} / \mathrm{kg}$, ip daily) significantly intensified the catabolic effect of prednisolone 21 -hemisuccinate sodium salt ( $7 \mathrm{mg} / \mathrm{kg}, s c$ daily) on body mass, but did not augment adrenal gland atrophy (Tab. 1).

Concurrent administration of propranolol and prednisolone did not significantly affect the mass of bones immediately after isolation, mass of lyophilized bones and mass of bone mineral (data not shown) in relation to controls. However, the ratios of bone mass, lyophilized bone mass and bone mineral mass to the body mass were increased in comparison to all other groups of rats (Tab. 2, data for the tibia not shown). In addition, the ratio of bone mineral mass to bone mass in L-4 vertebra was markedly increased. Calcium content in the bone mineral was not significantly affected (data not shown).
The effects of concurrent administration of propranolol and prednisolone on mechanical properties of the tibial metaphysis and femoral neck were similar to those of propranolol alone (Tab. 3). In addition, the histomorphometric parameters of rats receiving both drugs remained similar to those of rats receiving each of the treatments alone (Tab. 4). Both TRACP $5 \mathrm{~b}$ and osteocalcin levels were significantly decreased in comparison to the control rats (Tab. 5).

\section{Discussion}

Suppression of bone formation is a central feature in the pathogenesis of glucocorticoid-induced osteoporosis. In humans, it occurs in two phases: a rapid, early phase in which bone mineral density is reduced possibly due to increased bone resorption, and a slower, progressive phase in which bone mineral density decreases due to impaired bone formation [9]. However, low-dose prednisone was reported to decrease bone formation markers and to decrease the bone resorption marker free urinary deoxypyridinoline in postmenopausal women, indicating the possibility of inhibition of bone resorption [38].

Although glucocorticoid-induced osteoporosis is the most common type of secondary osteoporosis, and glucocorticoid excess is one of the most frequently identified causes of male osteoporosis [20], its experimental rat model is not well established [21]. A recent study of Ogoshi et al. [25] demonstrated that 6-monthold female rats treated with $20 \mathrm{mg} / \mathrm{kg}$ prednisolone sodium succinate $(s c)$ for 4 weeks were suitable models for glucocorticoid-induced osteoporosis, with a dominant cancellous bone decrease and reduced bone turnover, both formation and resorption. Our observations from the current study on male rats of a similar age (24 weeks) given prednisolone 21-hemisuccinate sodium salt at a dose of $7 \mathrm{mg} / \mathrm{kg}$ daily for 4 weeks are consistent with their results. In our previous study, we used prednisolone $(5 \mathrm{mg} / \mathrm{kg}$, im) in young adult male rats, which caused changes in bone histomorphometric parameters, including a decrease in bone formation and an increase in bone resorption, but also a too profound decrease in body mass [14]. Administration of prednisolone 21-hemisuccinate sodium salt $(7 \mathrm{mg} / \mathrm{kg}$, $s c$ daily) to 6-week-old male rats resulted in only a moderate decrease in body mass gain and changes in 
some bone histomorphometric parameters, but not in bone mass and mineralization [17].

In the present study, prednisolone caused adrenal atrophy due to the inhibition of the hypothalamuspituitary-adrenal axis and exerted a catabolic effect, that is, a decrease in the body mass. Prednisolone did not significantly affect bone mass, the mass of bone mineral and their ratio to the body mass or bone mineralization, but it induced significant changes in the rat skeletal system, leading to a decline of the mechanical properties of cancellous bone (tibial metaphyses). Because the decrease in body mass induced by prednisolone was moderate, although the body mass gain was significantly different from the control rats, the observed skeletal changes were probably not the result of body wasting. In histomorphometric measurements, inhibition of compact bone formation was demonstrated, including a decrease in periosteal transverse growth and in the width of the osteoid in the tibial diaphysis. Bone resorption of the compact bone seemed to be inhibited because the crosssectional area of the femoral marrow cavity tended to decrease. In the cancellous bone of the femur, the width of the trabeculae was profoundly decreased, which could be due to a decrease in bone formation and/or an increase in bone resorption. Serum osteocalcin levels, a marker of bone formation, tended to decrease, and serum TRACP 5b levels significantly decreased. TRACP $5 \mathrm{~b}$ is an osteoclastic enzyme; its level indicates the number of osteoclasts rather than their activity. The decreased TRACP 5b level can indicate both decreased bone resorption due to a lower osteoclast number, and a lower number of osteoclasts due to the bone loss induced by prednisolone treatment. In conclusion, 4-week prednisolone administration caused inhibition of both bone formation and resorption, consistent with a previous study [25].

At present, bisphosphonates (antiresorptive drugs) are considered to be the first line option for the treatment of glucocorticoid-induced osteoporosis [9-11]. However, because the dominant bone-damaging mechanism in glucocorticoid-induced osteoporosis is the inhibition of bone formation, we decided to study effects of propranolol, a drug that should stimulate bone formation and inhibit bone resorption. Propranolol blocks both $\beta_{1}$ - and $\beta_{2}$-adrenergic receptors and does not have any intrinsic sympathomimetic activity [18]. Recent data indicate that the sympathetic nervous system takes part in the regulation of bone metabolism $[13,19,36]$. In murine osteoblasts, only the presence of $\beta_{2}$-receptors has been reported [36], and the positive effects of $\beta$-blockers on the skeletal system in experimental conditions are attributed to $\beta_{2}$-receptors [18]. However, in humans, favorable effects on the fracture rate were reported also after administration of cardioselective $\beta$-blockers ( $\beta_{1}$-receptor antagonists) $[18,19]$.

In the present study, we used propranolol hydrochloride at a dose of $10 \mathrm{mg} / \mathrm{kg}$, ip daily. Previously, we used propranolol hydrochloride at a dose of $10 \mathrm{mg} / \mathrm{kg}$, po in ovariectomy-induced osteoporosis, which counteracted some changes developing in the skeletal system due to estrogen deficiency [34]. However, to our surprise, propranolol induced deleterious effects in the skeletal system of 24-week old male rats.

Administration of propranolol did not affect the body mass gain in rats, and the ratios of bone mass and lyophilized bone mass to body mass tended to decrease in comparison to the control rats. However, there was not a deleterious effect on bone mineralization, because the ratios of bone mineral mass to bone mass or lyophilized bone mass and calcium content in the bone mineral were not affected. Histomorphometric measurements demonstrated that propranolol decreased compact bone formation (a decrease in osteoid width and a strong tendency to decrease periosteal transverse growth), and bone resorption (a decrease in transverse cross-sectional area of the marrow cavity). Serum bone turnover marker measurements confirmed the inhibition of bone formation (a significant decrease in osteocalcin levels) and demonstrated a slight tendency to decrease osteoclast number as shown by TRACP 5b levels. The decrease in trabeculae width could be due to the inhibition of bone formation and/or intensification of bone resorption in the cancellous bone. The changes in bone structure caused a decline in the mechanical properties of the cancellous bone in tibial metaphysis. Taken together, the results of the present study demonstrated a damaging effect of propranolol hydrochloride $(10 \mathrm{mg} / \mathrm{kg}$, ip) on the skeletal system of mature male rats.

To our knowledge, the deleterious skeletal effects of propranolol have not been reported so far. The reasons for the damaging skeletal effects of the $\beta$-adrenergic blockade can only be speculated. Bonnet et al. [6] observed that the effect of propranolol on the skeletal system of ovariectomized rats depended on the dose used. The best results in counteracting the development of osteoporosis were demonstrated after administration of a very low dose $(0.1 \mathrm{mg} / \mathrm{kg}, s c)$; 
there was a weaker effect with $5 \mathrm{mg} / \mathrm{kg}$, $s c$ and practically no effect with the highest dose $(20 \mathrm{mg} / \mathrm{kg}, s c)$. The effect of the lowest dose was consistent with the early observation of Minkowitz et al. [24] and subsequent studies of Bonnet et al. [3, 4]. There was an attenuated antiosteoporotic effect of propranolol at 10 $\mathrm{mg} / \mathrm{kg} /$ day po compared to 0.1 and $1 \mathrm{mg} / \mathrm{kg} /$ day $p o$ in spontaneously hypertensive rats; however, no deleterious effect of propranolol at 50 and $100 \mathrm{mg} / \mathrm{kg} / \mathrm{day}$ po on the trabecular microarchitecture of bones was reported [31]. Positive effects of propranolol were reported after its use in drinking water $(500 \mathrm{mg} / \mathrm{l})$ in rats with bone changes induced by mechanical unloading [22] and in other rat studies [1, 42]. In rapidly growing 6-week-old male rats, propranolol hydrochloride $(10 \mathrm{mg} / \mathrm{kg} / \mathrm{day}$ po) increased bone mineralization [17]. Propranolol is almost completely absorbed after oral administration, but it undergoes hepatic first-pass metabolism [26]. It is possible that impact of the propranolol hydrochloride dose of $10 \mathrm{mg} / \mathrm{kg}$, ip was actually larger than that of $10 \mathrm{mg} / \mathrm{kg}$, po and that propranolol has biphasic effects on the skeletal system, where it is protective at lower doses and harmful at higher ones.

Although propranolol nonselectively blocks adrenergic receptors, it seems to have a larger affinity to the $\beta_{2}$-than the $\beta_{1}$-receptor [2]. The role of each receptor type in bones is not precisely known; however, it was demonstrated that mice lacking $\beta_{2}$-receptors and mice depleted of $\beta_{1^{-}}, \beta_{2^{-}}$and $\beta_{3}$-receptors had higher bone mass, whereas mice lacking $\beta_{1}$ - and $\beta_{2}$-receptors had decreased bone formation indices and lowered cortical bone volume $[7,8,19]$. It seems likely that propranolol at lower doses may block mainly $\beta_{2}$-receptors in bone cells and favorably affect the skeletal system, whereas at higher doses, propranolol may block $\beta_{1}$ and $\beta_{2}$-receptors and decrease bone formation. In fact, the effects of propranolol in the present study seem to resemble the phenotype of mice lacking $\beta_{1^{-}}$and $\beta_{2^{-}}$ receptors [7]. The unfavorable effects of propranolol in the present study could be also connected with its cardiovascular (hypotensive) effects, which might have decreased the blood supply to the bone.

Concurrent administration of propranolol and prednisolone strongly intensified the catabolic effect of prednisolone on body mass. The dual treatment also augmented the deleterious effects of both treatments alone on some skeletal parameters. Profound changes in the ratios of bone mass and bone mineral mass to body mass in relation to all other groups of rats resulted mainly from the changes in body mass, yet slight tendencies observed for rats receiving prednisolone alone in relation to the control group became strongly significant after the simultaneous administration of both drugs. However, mineralization of the cancellous bone increased, as measured as the ratio of bone mineral mass to bone mass in the vertebra. Bone formation was significantly inhibited and the mechanical properties tended to decline in relation to control rats. Taken together, propranolol at the dose used in the present study did not counteract the development of prednisolone-induced changes in the skeletal system in rats.

The results of the present study, showing the damaging effects of propranolol on the rat skeletal system, may help to understand the equivocal results of clinical trials. Although favorable associations between $\beta$-blocker use and bone mineral density or fracture risk were reported in the majority of the human studies $[5,27,30,32]$, some studies found no effect or unfavorable associations $[28,29]$. It is possible that $\beta$ adrenergic receptor antagonists exert biphasic effects, favorable and deleterious, on the skeletal system not only in rats, but also in humans, depending on the dose or individual susceptibility.

\section{References:}

1. Baek K, Bloomfield SA: $\beta$-Adrenergic blockade and leptin replacement effectively mitigate disuse bone loss. J Bone Miner Res, 2009, 24, 792-799.

2. Baker JG: The selectivity of $\beta$-adrenoceptor antagonists at the human $\beta_{1}, \beta_{2}$ and $\beta_{3}$ adrenoceptors. Br J Pharmacol, 2005, 144, 317-322.

3. Bonnet N, Beaupied H, Vico L, Dolleans E, Laroche N, Courteix D, Benhamou CL: Combined effects of exercise and propranolol on bone tissue in ovariectomized rats. J Bone Miner Res, 2007, 22, 578-588.

4. Bonnet N, Benhamou CL, Malaval L, Goncalves C, Vico L, Eder V, Pichon C, Courteix D: Low dose $\beta$-blocker prevents ovariectomy-induced bone loss in rats without affecting heart functions. J Cell Physiol, 2008, 217, 819-827.

5. Bonnet N, Gadois C, McCloskey E, Lemineur G, Lespessailles E, Courteix D, Benhamou CL: Protective effect of $\beta$ blockers in postmenopausal women: influence on fractures, bone density, micro and macroarchitecture. Bone, 2007, 40, 1209-1216.

6. Bonnet N, Laroche N, Vico L, Dolleans E, Benhamou CL, Courteix D: Dose effects of propranolol on cancellous and cortical bone in ovariectomized adult rats. J Pharmacol Exp Ther, 2006, 318, 1118-1127. 
7. Bonnet N, Pierroz DD, Ferrari SL: Adrenergic control of bone remodelling and its implications for the treatment of osteoporosis. J Musculoskelet Neuronal Interact, 2008, 8, 94-104.

8. Bouxsein ML, Devlin MJ, Glatt V, Dhillon H, Pierroz DD, Ferrari SL: Mice lacking $\beta$-adrenergic receptors have increased bone mass, but are not protected from deleterious skeletal effects of ovariectomy. Endocrinology, 2009, 150, 144-152.

9. Canalis E, Mazziotti G, Giustina A, Bilezikian JP: Glucocorticoid-induced osteoporosis: pathophysiology and therapy. Osteoporos Int, 2007, 18, 1319-1328.

10. Compston J: Management of glucocorticoid-induced osteoporosis. Nat Rev Rheumatol, 2010, 6, 82-88.

11. de Nijs RNJ: Glucocorticoid-induced osteoporosis: a review on pathophysiology and treatment options. Minerva Med, 2008, 99, 23-43.

12. de Vries F, Souverein PC, Cooper C, Leufkens HG, van Staa TP: Use of $\beta$-blockers and the risk of hip/femur fracture in the United Kingdom and The Netherlands. Calcif Tissue Int, 2007, 80, 69-75.

13. Elefteriou F: Regulation of bone remodeling by the central and peripheral nervous system. Arch Biochem Biophys, 2008, 473, 231-236.

14. Folwarczna J, Janiec W, Firlus K, Kaczmarczyk-Sedlak I: Effects of doxycycline on the development of bone damage caused by prednisolone in rats. Pol J Pharmacol, 1999, 51, 243-251.

15. Folwarczna J, Janiec W, Gawor M, Pytlik M, Kaczmarczyk-Sedlak I, Nowińska B: Effects of enoxaparin on histomorphometric parameters of bones in rats. Pol J Pharmacol, 2004, 56, 451-457.

16. Folwarczna J, Janiec W, Śliwiński L: Effects of heparin and low-molecular-weight heparins on bone mechanical properties in rats. Thromb Haemost, 2004, 92, 940-946.

17. Folwarczna J, Śliwiński L, Kulig M, Nowińska B, Cegieła U, Pytlik M, Kaczmarczyk-Sedlak I, Trzeciak HI: Effect of propranolol on the glucocorticoid-induced bone changes in young rats. Calcif Tissue Int, 2007, 80, Suppl 1, S126-S127 (abstract).

18. Graham S, Hammond-Jones D, Gamie Z, Polyzois I, Tsiridis E, Tsiridis E: The effect of $\beta$-blockers on bone metabolism as potential drugs under investigation for osteoporosis and fracture healing. Expert Opin Investig Drugs, 2008, 17, 1281-1299.

19. Hamrick MW, Ferrari SL: Leptin and the sympathetic connection of fat to bone. Osteoporos Int, 2008, 19, 905-912.

20. Kamel HK: Male osteoporosis: new trends in diagnosis and therapy. Drugs Aging, 2005, 22, 741-748.

21. Lelovas PP, Xanthos TT, Thoma SE, Lyritis GP, Dontas IA: The laboratory rat as an animal model for osteoporosis research. Comp Med, 2008, 58, 424-430.

22. Levasseur R, Sabatier JP, Potrel-Burgot C, Lecoq B, Creveuil C, Marcelli C: Sympathetic nervous system as a transmitter of mechanical loading in bone. Joint Bone Spine, 2003, 70, 515-519.

23. Meisinger C, Heier M, Lang O, Döring A: $\beta$-Blocker use and risk of fractures in men and women from the general population: the MONICA/KORA Augsburg cohort study. Osteoporos Int, 2007, 18, 1189-1195.
24. Minkowitz B, Boskey AL, Lane JM, Pearlman HS, Vigorita VJ: Effects of propranolol on bone metabolism in the rat. J Orthop Res, 1991, 9, 869-875.

25. Ogoshi T, Hagino H, Fukata S, Tanishima S, Okano T, Teshima R: Influence of glucocorticoid on bone in 3-, 6-, and 12-month-old rats as determined by bone mass and histomorphometry. Mod Rheumatol, 2008, 18, 552-561.

26. Okabe H, Higashi T, Ohta T, Hashimoto Y: Intestinal absorption and hepatic extraction of propranolol and metoprolol in rats with bilateral ureteral ligation. Biol Pharm Bull, 2004, 27, 1422-1427.

27. Pasco JA, Henry MJ, Sanders KM, Kotowicz MA, Seeman E, Nicholson GC: $\beta$-Adrenergic blockers reduce the risk of fracture partly by increasing bone mineral density: Geelong osteoporosis study. J Bone Miner Res, 2004, 19, 19-24.

28. Reid IR, Gamble GD, Grey AB, Black DM, Ensrud KE, Browner WS, Bauer DC: $\beta$-Blocker use, BMD, and fractures in the study of osteoporotic fractures. J Bone Miner Res, 2005, 20, 613-618.

29. Rejnmark L, Vestergaard P, Kassem M, Christoffersen BR, Kolthoff N, Brixen K, Mosekilde L: Fracture risk in perimenopausal women treated with $\beta$-blockers. Calcif Tissue Int, 2004, 75, 365-372.

30. Rejnmark L, Vestergaard P, Mosekilde L: Treatment with beta-blockers, ACE inhibitors, and calcium-channel blockers is associated with a reduced fracture risk: a nationwide case-control study. J Hypertens, 2006, 24, 581-589.

31. Sato T, Arai M, Goto S, Togari A: Effects of propranolol on bone metabolism in spontaneously hypertensive rats. J Pharmacol Exp Ther, 2010, 334, 99-105.

32. Schlienger RG, Kraenzlin ME, Jick SS, Meier CR: Use of $\beta$-blockers and risk of fractures. JAMA, 2004, 292, $1326-1332$.

33. Stürmer EK, Seidlová-Wuttke D, Sehmisch S, Rack T, Wille J, Frosch KH, Wuttke W, Stürmer KM: Standardized bending and breaking test for the normal and osteoporotic metaphyseal tibias of the rat: effect of estradiol, testosterone, and raloxifene. J Bone Miner Res, 2006, 21, 89-96.

34. Śliwiński L, Folwarczna J, Kaczmarczyk-Sedlak I, Pytlik M, Cegieła U, Trzeciak HI: Effects of propranolol on the skeletal system of non-ovariectomized and ovariectomized rats. Calcif Tissue Int, 2008, 82, Suppl 1, S224-S225 (abstract).

35. Takeda S, Elefteriou F, Levasseur R, Liu X, Zhao L, Parker KL, Armstrong D, Ducy P, Karsenty G: Leptin regulates bone formation via the sympathetic nervous system. Cell, 2002, 111, 305-317.

36. Takeda S, Karsenty G: Molecular bases of the sympathetic regulation of bone mass. Bone, 2008, 42, 837-840.

37. Togari A, Arai M: Pharmacological topics of bone metabolism: the physiological function of the sympathetic nervous system in modulating bone resorption. J Pharmacol Sci, 2008, 106, 542-546.

38. Ton FN, Gunawardene SC, Lee H, Neer RM: Effects of low-dose prednisone on bone metabolism. J Bone Miner Res, 2005, 20, 464-470.

39. Turner CH, Burr DB: Basic biomechanical measurements of bone: a tutorial. Bone, 1993, 14, 595-608. 
40. van Brussel MS, Bultink IEM, Lems WF: Prevention of glucocorticoid-induced osteoporosis. Expert Opin Pharmacother, 2009, 10, 997-1005.

41. Wiens M, Etminan M, Gill SS, Takkouche B: Effects of antihypertensive drug treatments on fracture outcomes: a meta-analysis of observational studies. J Intern Med, 2006, 260, 350-362.
42. Zhang W, Kanehara M, Zhang Y, Wang X, Ishida T: $\beta$-Blocker and other analogous treatments that affect bone mass and sympathetic nerve activity in ovariectomized rats. Am J Chin Med, 2007, 35, 89-101.

Received: November 9, 2010; in the revised form: March 21, 2011; accepted: April 14, 2011. 